\title{
Designing Value into Engineering Learning Through Service Activities Using a Blueprint Model
}

\author{
Kurtis G. Paterson \\ Head, Department of Engineering \\ James Madison University \\ 801 Carrier Drive - MSC 4113 \\ Harrisonburg, VA 22807 \\ paterskg@jmu.edu \\ Christopher W. Swan \\ Associate Professor, Department of Civil \& \\ Environmental Engineering \\ Tufts University \\ Medford, MA 02155 \\ chris.swan@tufts.edu \\ David Kazmer \\ Professor, Dept. Plastics Engineering \\ University of Massachusetts Lowell \\ 223 Ball Hall, 1 University Ave \\ Lowell, MA 01854 \\ David_Kazmer@uml.edu
}

\author{
Angela R. Bielefeldt \\ Professor, Department of Civil, Environmental \& \\ Architectural Engineering \\ University of Colorado Boulder \\ Boulder, CO 80309 \\ Angela.Bielefeldt@colorado.edu \\ Greg Rulifson \\ PhD student, Department of Civil, Environmental \& \\ Architectural Engineering \\ University of Colorado Boulder \\ Boulder, CO 80309 \\ grulifson@gmail.com \\ Olga Pierrakos \\ Associate Professor, Department of Engineering \\ James Madison University \\ 801 Carrier Drive - MSC 4113 \\ Harrisonburg, VA 22807 \\ pierraox@jmu.edu
}

Abstract - Both course-based service-learning (S-L) and extracurricular community service activities, together referred to as Learning Through Service, provide the opportunity for rich learning, personal growth, and tangible beneficial outcomes for students, community partners, and faculty. However, to fully realize this potential careful planning and design of the Learning Through Service (LTS) effort are required. This paper describes a framework with nine important elements to consider for LTS program design: (1) stakeholders, (2) value propositions, (3) relationships, (4) channels, (5) key activities, (6) resources, (7) partnerships, (8) value stream returns, and (9) value stream costs/outlays. This LTS development framework is based on the Business Canvas Model used in developing and evaluating the business viability of an innovative product or service. For LTS, the stated program design attributes were identified based on the personal LTS experience of the research team and input from additional experts. These nine elements can be effectively presented as a blueprint for an LTS program. Thoughtful planning in each of these areas will help ensure that the program goals are met and provide optimal benefits for all of the stakeholders. These elements also help to identify where management and assessment efforts are best targeted. Specific examples for each of the nine attributes from thirty-four different LTS programs are presented. Some of these LTS programs were in the planning phases and missing elements that could make the programs more meaningful, such as student reflection or engaging community partners as equals. Together, the model and examples provide guidance for others who are interested in designing a new LTS program, or improving an existing one.

Index Terms -program design, value propositions, partnerships, resources. 


\section{INTRODUCTION}

An increasing number of learning through service (LTS) programs are being developed in engineering ${ }^{1}$. These partnerships offer excellent educational opportunities for student learning while providing benefits to communities. ${ }^{2,3}$ In many cases, LTS programs are realized through service-learning (S-L) courses, ${ }^{4}$ many of which have become common in engineering for first year students, ${ }^{5-7}$ capstone senior design, ${ }^{8}$ and various electives. Some programs have also incorporated S-L into core required engineering science courses. ${ }^{9}$ Alternatively, extracurricular community-based activities focused on serving partners can provide rich learning experiences for students. Examples of such activities are projects with Habitat for Humanity, ${ }^{10-14}$ Engineers Without Borders-USA (EWB-USA), ${ }^{15-17}$ and Bridges To Prosperity (BTP). ${ }^{18}$

Despite their apparently good outcomes, some faculty hesitate to become involved with LTS activities due to a lack of knowledge about interested community partners, concerns with time demands, or other issues. ${ }^{19-20}$ Other faculty dive into LTS with good intentions but little understanding of how to build partnerships and programs that will best benefit both students and communities. Both approaches result in engineering programs that do not meet their full potential to educate students and meet the needs of society. Even when present in engineering courses, student learning goals generally take top priority, perhaps to the detriment of positive outcomes for community partners. ${ }^{8,21-22}$

While we encourage faculty to "start small rather than not at all", 23 our intent is to provide engineering faculty with tools to assist them in designing effective LTS programs that meet their goals. Previous work on how to design an effective LTS program is limited. Best practices for S-L have been previously proposed, ${ }^{24-27}$ but some of these elements pertain more to community service placement types of S-L rather than the more typical engineering model of project-based design. These best practices also tend to lack practical information on how to meet these goals. Sandmann et al. ${ }^{28}$ proposed a Service-Learning Program Planning Model that included the five dimensions of research, relationships, roles and responsibilities, representation, and resources. However, it is unclear that this model will be sufficient for LTS in engineering, which tends to focus on project-based learning and is broader than only S-L. The purpose of this paper is to describe a blueprint model that could assist LTS leaders and practitioners in designing and implementing effective programs. This blueprint provides a structured reflection and design exercise to create new LTS programs or refine existing activities. This paper describes the development of the blueprint and its nine critical design elements, as well as results from more than thirty engineering leaders who used this process for their own LTS program. The unique characteristics of each LTS program will determine which of the ideas included in other blueprints may be helpful.

\section{METHODS}

The research team is conducting a broad study to understand faculty motivations for participation in LTS, distill best practices for LTS, and teach engineering faculty how to create effective LTS programs. Toward these efforts, an "Engineering Faculty Engagement in Learning through Service Summit" was convened at the University of Colorado Boulder in September 2011. ${ }^{29}$ Twenty-five individuals with expertise in teaching, organizing, or assessing LTS programs were invited to participate. There were also eleven facilitators from the research team, which included faculty, staff, and graduate students. During the two-day summit, participants engaged in a 
variety of individual and small group activities. In particular, the participants were asked to recommend best practices for LTS program design, management, and assessment. Each of these attributes was considered from the perspective of students, community partners, faculty, and the university.

After the summit the research team carefully considered the input from these LTS experts. From this information, the authors led the research team in adapting a non-profit business model canvas ${ }^{30}$ to serve as a tool that would help design effective LTS programs. The resulting blueprint contained nine important elements to consider for LTS program design: (1) stakeholders, (2) value propositions, (3) relationships, (4) channels, (5) key activities, (6) resources, (7) partnerships, (8) value returns; and (9) value costs and outlays. This blueprint was configured with an open box for each of the nine program design attributes (Figure 1). Each box included a few starter questions to drive content creation for each of the nine domains. For example, the starter questions for stakeholders were: For whom are you creating value? Who are your most important stakeholders? Starter questions for the other elements are shown in Figure 1. Blueprints were printed 3-feet by 5-feet on poster-size paper and provided to the participants at two LTS workshops in 2012. ${ }^{31-32}$

A call for LTS workshop applicants was distributed via the American Society for Engineering Education (ASEE) and other venues. Applicants described their interest in LTS and an LTS program that they were interested in designing or refining. Multiple individuals from the same program or university were encouraged to apply. This process resulted in thirty-seven participants who were involved with thirty-four different LTS programs at an array of engineering schools. The workshop participants represented programs housed at a college-level (21 participants were from engineering administration, education, teaching, leadership, design or technology centers / institutes / programs) and/or a range of programs ( 7 from civil and/or environmental engineering, 3 from biological / agricultural engineering, 2 from mechanical engineering; also chemical engineering, computer science, construction management). The participants' level of experience associated with LTS included novice (17\% with little to no LTS experience), intermediate (53\%, 1-5 years LTS involvement), and advanced (31\% with more than 5 years of experience and/or publications on LTS).

During the two-day workshops, participants were led through a variety of individual and small group activities, ${ }^{31-32}$ many which included design (or re-design) of their own LTS program following the LTS Program Model Blueprint. The blueprint shown in Figure 1 is a "synthesis" of all the blueprints created, in which the size of the word represents the proportion of participants who included the particular theme in their blueprint. At the first workshop, the nine design domains on the blueprint were initially explored on worksheets, for about 15 minutes each. In some cases the exploration occurred initially in small groups. Then time was provided to transfer these ideas onto the blueprint. The second workshop was nearly identical except that participants were given more time to work directly on their blueprint rather than first using worksheets and transferring the ideas. The participants at the second workshop were also given the opportunity to share their blueprint in a round-robin "poster" style session upon completion. 


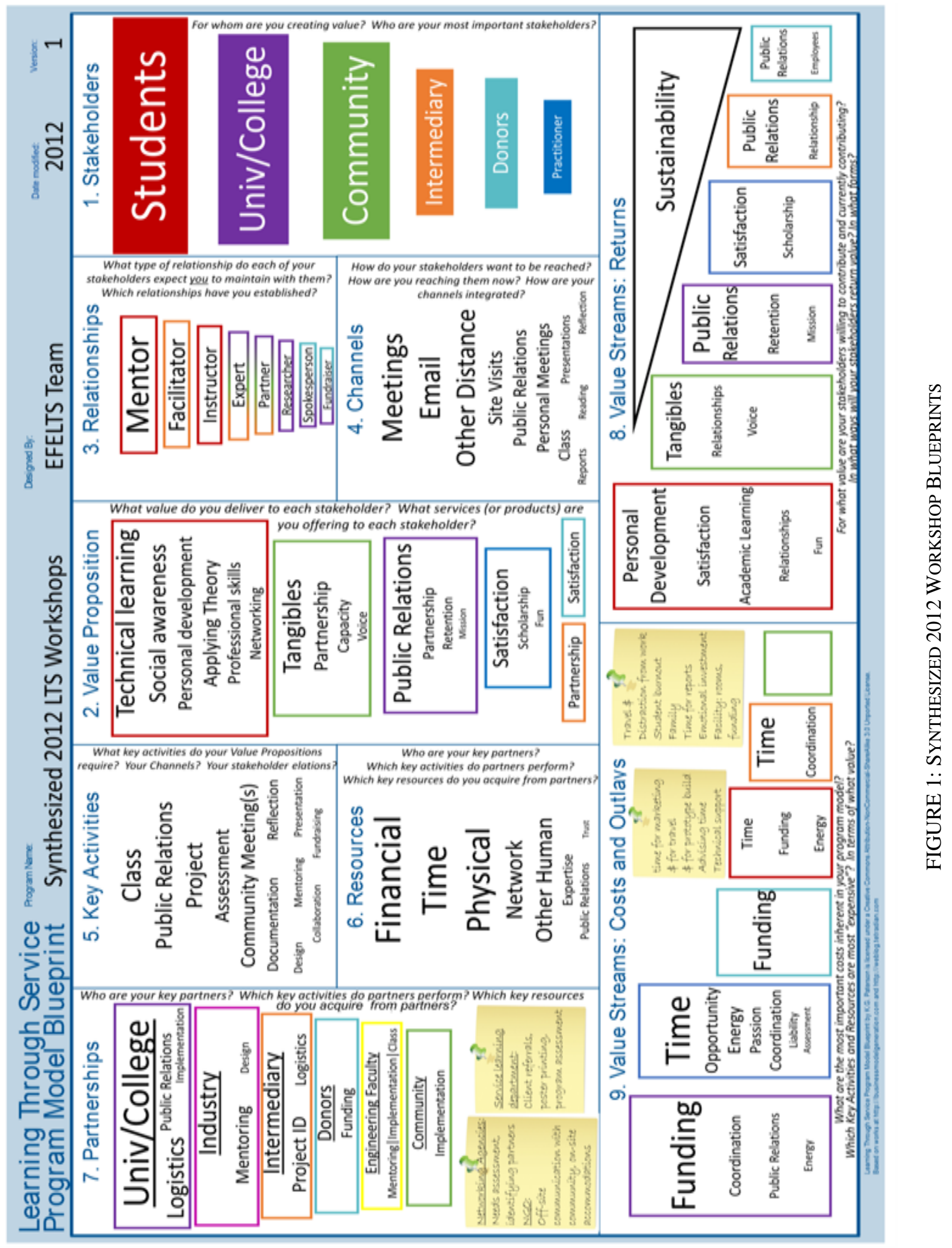


Some sections of some blueprints were blank, perhaps because the individual chose to record their ideas on the worksheet rather than the blueprint and/or the participants were "networking" rather than completing the assigned activity. A few general attributes of the LTS programs represented at the workshops are summarized in Table I.

TABLE I

GENERAL ATtRIBUtes of LTS PROGRAMS DESIGNED AT THE WORKSHOPS

\begin{tabular}{cc|ccc}
\hline LTS Program Type & All 34 & Required Course & Elective Course & Extracurricular \\
\hline All 34 & $100 \%$ & $23 \%$ & $53 \%$ & $24 \%$ \\
\hline Location: & & & & \\
International & $38 \%$ & $0 \%$ & $20 \%$ & $18 \%$ \\
Domestic & $56 \%$ & $23 \%$ & $27 \%$ & $6 \%$ \\
Both Domestic and International & $6 \%$ & $0 \%$ & $6 \%$ & $0 \%$ \\
\hline Rank of Student Participants: & & & & \\
Upper Division & $41 \%$ & $6 \%$ & $26 \%$ & $9 \%$ \\
Lower Division & $32 \%$ & $11 \%$ & $15 \%$ & $6 \%$ \\
All Levels & $27 \%$ & $6 \%$ & $12 \%$ & $6 \%$ \\
\hline
\end{tabular}

The blueprints that were generated by the participants were photographed and returned to their creator for further use at their home institutions. Following the workshop, content analysis of the blueprints was conducted. This involved first transcribing the text from each of the nine LTS design element boxes into a spreadsheet. Data analysis began with the iterative development of a coding framework. Thematic network analysis, recommended by Attride-Stirling ${ }^{33}$ was deemed most appropriate because it allowed for the systematic extraction of common themes and evaluation of the relative importance of each. A coding framework was developed by noting common thematic threads surfacing in the responses. ${ }^{33}$ Subsequently, these groups were merged into common themes. ${ }^{33}$ For example, the student theme included current undergraduate students, graduate students, and prospective students. Additionally, the clustering of themes was followed by matrix coding in $\mathrm{Nvivo}^{34}$ to compare the classifications or identifying information of a practitioner or a program to their responses. This analysis was done to identify any patterns between program attributes; the following results may help practitioners relate their programs and experience to similar programs for inspiration about how to proceed. However, predominant themes in the blueprints should not be interpreted as best practices, as they represent both a timelimited exercise and a wide range of participant knowledge and experience with LTS.

\section{LTS Program Design AtTributes ANd Results}

The LTS Program Model Blueprint was designed to work for any type of endeavor including a whole integrated program, academic courses, elective courses, or even an extracurricular experience. The blueprint helps to ensure that the LTS program is designed holistically and takes various goals into account by incorporating the perspective of all stakeholders involved. This exercise may help course instructors to broaden their focus beyond student learning to more fully consider the needs and goals of their community partners, college administrators, and financial supporters, among others. It may also help extracurricular service projects to go beyond thinking of the community from a deficit perspective to a greater realization of the broad range of benefits that community involvement can impart to students. These reciprocal 
relationships where engineering students truly partner with community members to co-create solutions are likely to be more beneficial for everyone involved. ${ }^{35-40}$ In reciprocal relationships, all partners (inclusive of students, community partners, and instructors) will learn, teach, be served, and provide service. ${ }^{35,41-42}$ There are nine program elements that are identified using the blueprint: (1) stakeholders, (2) program value, (3) relationships, (4) channels, (5) key activities, (6) resources, (7) partnerships, (8) value returns; and (9) value costs and outlays. Below, each of these attributes will be described, and examples of outcomes from the design process by the thirty-four different LTS programs will be presented. Note that the workshop participants were functioning under time constraints and therefore unlikely to fully develop their ideas for each element. While the blueprint domains are presented numerically, an individual designer may want to consider each one sequentially or not, but then iterate between these attributes as synergies emerge.

\section{Stakeholders}

The best place to start the process of designing an LTS program is to consider the stakeholders. This necessitates thinking about the people and groups for whom the practitioner plans to create value. While it can be helpful to try to be exhaustive with this list, it is also valuable to determine the most important stakeholders. Examples of common LTS stakeholders include: students, community members, colleagues, alumni, administrators, non-governmental organizations (NGOs), businesses, government, universities, and the public. From the blueprints of the workshop participants, the number of different stakeholders listed by any single LTS program ranged from three to ten, with a median of five. A summary of the stakeholders and the percentage of the blueprints that listed these stakeholders is shown in Table II. The size of these stakeholders shown on the synthesis blueprint in Figure 1 reflects the frequency with which they appeared on the 34 blueprints.

TABLE II

DIFFERENT LTS STAKEHOLDERS (PERCENTAGE OF LTS BLUEPRINTS), N=34

\begin{tabular}{lc|cc|ccc}
\hline \multicolumn{1}{c}{ Stakeholders } & All & $\begin{array}{c}\text { Course- } \\
\text { Based (79) }\end{array}$ & $\begin{array}{c}\text { Extracurricular } \\
(\mathbf{1 0 0})\end{array}$ & $\begin{array}{c}\text { International } \\
\mathbf{( 4 2 )}\end{array}$ & $\begin{array}{c}\text { Domestic } \\
\mathbf{( 3 4 )}\end{array}$ & $\begin{array}{c}\text { Both } \\
\mathbf{( 2 4 )}\end{array}$ \\
\hline Students & 100 & 100 & 100 & 100 & 100 & 100 \\
Community & 88 & 85 & 86 & 86 & 75 & 100 \\
University/college & 79 & 77 & 86 & 79 & 75 & 88 \\
Intermediary & 62 & 62 & 71 & 64 & 58 & 63 \\
LTS practitioner/ & 53 & 65 & 57 & 71 & 75 & 63 \\
faculty & & & & & & \\
Donors & 15 & 8 & 43 & 36 & 17 & 13 \\
Alumni & 12 & 19 & 14 & 29 & 8 & 0 \\
LTS program staff & 12 & 12 & 14 & 14 & 17 & 38 \\
Industry & 3 & 4 & 0 & 5 & 8 & 13 \\
\hline
\end{tabular}

Students participating in the LTS program were listed on all of the blueprints, compared to $30(88 \%)$ that included some form of the community partner (such as community, community partner, or community members). Given the definition of LTS, rooted in S-L ${ }^{2,43-44}$, all LTS programs should consider both students and community partners as key stakeholders. A closer exploration of the four LTS programs that did not include community as a partner shows that in 
one case the perceived partners receiving service were identified by other terms that were more indicative of client-style relationships: owners-private, government, commercial; some of this may be the disciplinary perception of civil engineers that communities and public agencies are our traditional clients. Three LTS programs identified an NGO partner; perhaps the LTS programs served the community via this intermediary but without direct community contact. On one LTS blueprint, no community partner was identified.

The next most common stakeholder group identified was the university, college, department, and/or administration. The faculty or instructor of the LTS experience, which we have termed "practitioner" or "lead" was indicated on $18(53 \%)$ of the blueprints. Additional stakeholders are shown in Table II, such as intermediaries (NGOs, K12 schools, churches), donors, alumni, LTS program staff (program coordinator), and industry. Other stakeholders listed by at least one person included: K12 teachers, industrial advisors, businesses, design reviewers, mentors, future employers, student affairs, local and state agencies, peer groups, future students. If industry and/or businesses are the primary partner with the LTS program, without a community or NGO partner, the activity would not meet the definition of S-L. ${ }^{2,44-45}$ But in this context where individual LTS programs listed between three to ten stakeholders, industry or business might be appropriately counted as a stakeholder. For example, in their capacity as future employers of the students who gain skills through the LTS experience, industry may be viewed as a stakeholder.

After the basic diversity of responses were classified, some explorations were conducted into whether or not different types of LTS programs considered different stakeholders. For example, the extracurricular LTS programs and programs that included both course-based and extracurricular elements (such as EWB programs at a couple of schools) much more commonly included donors and alumni as stakeholders, compared to the course-based LTS programs. LTS programs that included international community partners were significantly more likely to include LTS program staff as stakeholders compared to local/domestic LTS programs. Therefore, while some stakeholders such as students, community, and practitioner are likely to be universal among all LTS programs, other stakeholders may or may not be relevant.

\section{Value Proposition}

The value proposition requires one to consider the benefits that are delivered to each stakeholder via involvement with the LTS program. To determine the value of the LTS program, one might consider what stakeholder opportunities the LTS program will help satisfy, what services or products are offered to each stakeholder, and what stakeholder needs are being satisfied. The number of different value propositions listed on individual blueprints ranged from 2 to 20, with a median of 10. The most common value propositions associated with the primary LTS stakeholders are summarized in Table III and shown in Figure 1 (with the color of the stakeholder in box 1 of the blueprint indicating attribution; for example, students participating in the LTS program are in red, community partners in green, and the lead/practitioners in dark blue). 
International Journal for Service Learning in Engineering

Special Edition, pp. 64-83, Fall 2013

ISSN 1555-9033

TABLE III

VALUE PROPOSITIONS FOR DIFFERENT LTS STAKEHOLDERS (\% OF ALL PROGRAMS), N=34

\begin{tabular}{llll}
\hline \multicolumn{1}{c}{ Students } & Community Partners & \multicolumn{1}{c}{ Lead } & University \\
\hline Technical learning (56) & Tangible product (91) & Satisfaction (26) & PR/recruiting (59) \\
Applying theory (50) & Capacity (29) & Scholarship (15) & Help meeting \\
Social awareness (50) & Partnerships (24) & Systemic improvement(9) & mission(26) \\
Professional skills (35) & Voice (21) & Personal development (9) & Retention (21) \\
Personal development (26) & Accountability (6) & Fun (3) & \\
Broad learning (21) & & & \\
Fun (3) & & & \\
\hline
\end{tabular}

The most common values listed for students were grouped into three main themes: academic learning, personal development, and social awareness. Academic learning included any proposed value that mentioned that students would learn technical information and/or professional skills (including teamwork, communication) better by learning it through a service project rather than in a typical course or extracurricular setting. These opportunities can be especially important to student participants because LTS projects can provide a venue to gain engineering experience in ways that traditional classes struggle to facilitate. Personal development related to individual awareness and identity, and included specific statements from the blueprints such as: personal transformation, confidence, personal fulfillment, self-awareness, and enhances desire to serve. Social awareness was the third key value achieved through these activities, mentioned by half of the workshop attendees. Simply put, students achieve a better understanding of the world through stakeholder interactions on a service project. This is critical for contextual, empathetic and effective design for most engineering projects in a modern world. Civic learning was considered a type of social awareness. The broad learning category included life-long, integrative, reciprocal, and social learning.

Some of the key values proposed regarding the community partners included: tangibles (new technology, solved problem, poverty alleviated), capacity (education, new income opportunities, organization), and voice (recognition of the community and their needs, exposure to the community, and sharing stories). Each of these are important on different levels of sustainability. Tangibles are almost always mentioned as the primary value the community receives from participating in an LTS program; not surprising as most engineering projects are infrastructure or "product" centric. Capacity indicates the community's ability to use, maintain, or modify these tangibles following the LTS experience. Frequently, the text on the blueprints was limited, so it is unclear if the partnerships referred to were always truly reciprocal, as is optimal for effective LTS programs. Voice suggests the community partners serve as codesigners in the project process, engaged in a reciprocal relationship with the project. The community value proposition underscores the need for true bi-directional communication, humility, patience, understanding and empathy among the stakeholders.

The value of participation to the LTS lead (faculty or staff) was less often discussed by the workshop participants (only 47\%); many program leads were apparently participating without consideration of the gains to themselves. However, among responses the most common was satisfaction with their teaching and student learning, followed by scholarship as some were able to weave LTS projects into research and publication pursuits. Additionally, LTS leaders were hoping to improve the entire department or the way classes are taught through systemic improvement. The university primarily benefitted through positive public relations $(P R)$ which 
could translate to student recruiting and alumni donations. Also included were student retention and fulfilling the mission of the university. Values that were proposed to additional stakeholders included capacity, networking and positive $P R$ for the intermediary partner (e.g. NGO, client, government body) and partnership with other institutions for working together on future learning through service projects.

Once these value propositions have been identified for a particular LTS program, assessment methods should be designed that allow a determination of whether these values are being realized. The workshop participants were asked to indicate on their blueprint which value propositions were currently not being assessed by underlining them. The number of the value propositions designated in this manner ranged from 0 to $100 \%$, some programs have robust assessment, many have inadequate plans, some none. Some individuals noted a mix of approaches to assess outcomes, some actually measured while others were informally evaluated. Additionally, a number of participants did not have any value propositions underlined. As it is unlikely that everything is being assessed in a program, these participants probably did not have enough time to critically think about what in their program needs to be assessed.

In addition, the importance of these value propositions to the LTS program should be determined and compared against the extent to which the program is realizing these benefits in order to distribute limited resources appropriately. This determination should be decided with contribution of stakeholders, rather than autonomously. Over time, the program can work to bring the importance and fulfillment into alignment such that the most important outcomes are being fully satisfied.

\section{Relationships}

In order to successfully realize the targeted value propositions for each stakeholder, appropriate relationships must be recognized, developed, and sustained. Stoecker and Tryon ${ }^{46}$ note "that there may be communication, cultural, and power issues in [LTS] relationships" and these potentially unequal relationships between the community and "academy" (LTS lead and/or students) will inhibit LTS from reaching its full potential. It is important to consider the types of relationships each stakeholder expects to be maintained with them. It takes time to build strong relationships, and these long-term relationships may yield optimal results for community partners. ${ }^{47-48}$ Therefore, it is important to consider any relationships that are already established. It is also important to consider how building and maintaining relationships is integrated into the rest of the LTS program. One should also consider the costs of building these relationships, in view of value and impact. A few examples of mechanisms for developing relationships (which are really the communication channels design element discussed below) are: electronic communication (web and email), personal interaction, learning community, community meetings, mentoring, and teaching.

The number of different relationships that were noted on the blueprints by 33 of 34 participants ranged from 3 to 13, with a median of 6 . Most participants listed their role in a relationship that is important for them to maintain with a given stakeholder. Frequently, the specific parties in a particular relationship were unclear. The most common relationships listed (and percentage of the 34 blueprints listing this relationship) were: mentor/coach (76\%), instructor/teacher (41\%), expert/source of knowledge (24\%), role model (21\%), collaborative (12\%), friend (12\%), and parent (12\%). Some of these terms likely described a type of relationship between the LTS faculty lead and the students (such as parent), although many of 
these relationships can also apply to the community partner (as mentor for students, role as a teacher and expert, etc. $\left.{ }^{49}\right)$. These ideas reflect varying degrees of equal collaboration / reciprocity versus an unequal power relationship. The LTS program design should aim to form equal and reciprocal relationships, where all of the key stakeholders are at various points teachers, learners, role models, and mentors. Petri ${ }^{49}$ found that communities expressed a desire for "jointly creating knowledge with the university" (pg. 198), which illustrates the importance that the community be viewed as more than merely an entity being "helped" because it is at some deficit. The relationships should be open and respectful, valuing the contributions and important role of all members. These types of relationships are most likely to yield optimal outcomes for all LTS participants. Sandmann et al. ${ }^{35}$ further note that the "success and sustainability of collaborative partnerships involving community- and university-based actors relies on the relationships amongst the partners."

Many of the workshop participants listed what role they would be playing in the program. Some unique roles listed for the practitioners were rabble-rouser, trailblazer, co-learner and listener. The terms mentor, coach, and co-learner are in line with best practices for servicelearning that call for this type of role for the faculty instructor. ${ }^{24}$

\section{Channels}

Channels are the delivery pathways for value between stakeholders. Communication, project infrastructure, system service, education and other common components of engineering LTS projects all need ways to flow among program participants. This is an important consideration as research has found that community partners "consistently cited problems in communication with faculty." 50 The LTS program should consider how the stakeholders want to be reached. If the program is operating, consider how they are currently being reached, how the channels are integrated, and if they match stakeholder routines. In addition, some channels are more effective than others, and these may be stakeholder specific. A few examples are: awareness through email list; evaluation via online survey; support through regular meetings; delivery by extended community visit; or a continuous relationship through social media. Some of these may be appropriate for on-campus participants, but options are limited when interacting with resourceconstrained and distant communities. A clear understanding of the needs and capabilities of each stakeholder is critical. Extended community visits tend to be a common model for international activities (e.g. EWB-USA, etc.) while course-based initiatives often rely on relationships between the lead and the intermediary partner or community.

All 34 participants filled out this section with a minimum of 1 channel, a maximum of 16, and a median of 7. Below is a table of channels with the stakeholders they would be reaching. Some are used for most stakeholders and were not specified on the blueprints individually, so these are included in the "General" column. Class time for S-L may be spent in a variety of ways, including traditional lectures as well as student-centered active learning. Some of the more unique channels described that gave evidence of thinking through the entire timeline were information sessions before the project starts, reading for the students to better understand the context of the project, and a client network to ensure sustainability and future projects building on those that have already occurred. 
Table IV

FREQUENT CHANNELS FOR KEY STAKEHOLDERS (\% OF ALL PROGRAMS), N=34

\begin{tabular}{llll}
\hline \multicolumn{1}{c}{ General } & \multicolumn{1}{c}{ Students } & \multicolumn{1}{c}{ Community } & \multicolumn{1}{c}{ Public } \\
\hline Email (88) & Class time / lecture (47) & Site visits (59) & Presentation (38) \\
Meetings (88) & Personal Meetings (53) & Client network (3) & Report (21) \\
Phone (41) & Assessment (35) & & Website (21) \\
\hline
\end{tabular}

\section{Key Activities}

In this element, the key actions and events needed to support the value propositions are crafted, taking into account the human and physical resources required. This is analogous to rigorous course design where the activities in the classroom (such as lectures, small group active learning exercises, etc.) and assignments for the students (whether homework, quizzes, design projects, etc.) are crafted to realize the learning objectives for the course. A few examples of LTS activities include: an information session, direct engagement with stakeholders, training, research/education, community project, and public symposium. Table V summarizes the results.

TABLE V

KEY ACTIVITIES OF, OR TARGETED TO, DIFFERENT STAKEHOLDERS (\% OF ALL PROGRAMS), N=29

\begin{tabular}{llll}
\hline \multicolumn{1}{c}{ Students } & \multicolumn{1}{c}{ Community Partners } & \multicolumn{1}{c}{ Lead } & \multicolumn{1}{c}{ University } \\
\hline Class Meetings (55) & Meeting with students (41) & Lecture (55) & Publicity (48) \\
Project implementation (48) & Project identification (31) & Documentation (31) & Logistics (48) \\
Reflection (31) & Project execution (21) & Mentor students (24) & Assessment of \\
Presentation (28) & & Fundraising (14) & project (41) \\
Visit community (24) & & & \\
Design project/product (24) & & & \\
\hline
\end{tabular}

Of the 34 blueprints, 29 described key activities. The number of different activities listed ranged from 1 to 9, with a median of 7 . From the workshop participants, the key activities tended to focus on the activities for students and secondarily for themselves, however many were about communication between the stakeholders. Some of the more common activities noted were meetings, project implementation, and presentation or assessment of the project.

Surprisingly, only $31 \%$ of the blueprints listed reflection as a student activity, despite this being widely considered an integral part of S-L. ${ }^{24,26}$ Hatcher \& Bringle ${ }^{51}$ suggest that reflection is an indispensable pedagogical component of LTS while Eyler \& Giles ${ }^{52}$ suggest reflection is the hyphen between service and learning in S-L. None of the novice workshop participants included reflection; the majority of the blueprints that stated reflection were from individuals with 6 or more years of LTS experience. These results indicate that more LTS practitioners in engineering need to be trained to understand the significance of reflection. It seems likely that effective integration of reflection may be a weakness in engineering $\mathrm{S}-\mathrm{L}^{53}$, and skepticism remains within engineering as to the benefits of reflection. ${ }^{54}$ The extracurricular nature of some LTS activities (such as EWB) may make it difficult to require students to complete reflection exercises, particularly engineering students who may resist reflection (and expressive writing in general $^{55}$ ). 
It also seemed that students should directly engage and listen to the community, as specific activities they are trained to do, versus merely meeting with project partners. ${ }^{56}$ While most of the details of the activities were specific to each project, some of the more interesting or ambitious ones that related to community partners included a project partner dinner, development of new skills for the community. For students, a novel activity mentioned by one participant was meditation. ${ }^{57}$ Additionally, $45 \%$ of the LTS blueprints mentioned that industry would provide mentoring, and $41 \%$ of the blueprints indicated that fund-raising was an activity with donors.

\section{Resources}

All LTS programs will need to have resources to function effectively. It is recommended to think of the resources that are required to successfully meet the goals of the value propositions. The channels to, and relationships with, each stakeholder will also require resources to be sustained. A few examples provided on the blueprints include: physical resources like equipment, information resources like GPS data, human resources like a village elder; financial resources like tuition; brand or your program's reputation; and trust such as long-term relationships.

Of the 34 blueprints from the workshops, 27 described ideas of resources for their programs. The number of different resources described ranged from 1 (trust) to 20 with a median of 6. Table VI summarizes the most commonly listed resources, grouped into themes. Not surprisingly, the more experienced LTS leads recognized the varied and extensive resources necessary. Some of the unique and important resources were: dedicated and collaborative staff, willingness to push personal limits, and appropriate problems to solve. Only one participant mentioned each of these, but they are good examples of the varied critical resources required for a sustainable and beneficial effort for all stakeholders.

TABLE VI

RESOURCES NEEDED FOR LTS PROGRAMS (\% OF ALL PROGRAMS), N=27

\begin{tabular}{llll}
\hline \multicolumn{1}{c}{ Human (89) } & \multicolumn{1}{c}{ Financial (67) } & \multicolumn{1}{c}{ Information (59) } & \multicolumn{1}{c}{ Physical (52) } \\
\hline Time (67) & General Funding (67) & Syllabus (26) & Tools (33) \\
Network (44) & Travel (22) & PR (19) & Communication (19) \\
Experts (30) & & Data (7) & Space (15) \\
Enthusiasm (7) & & & \\
\hline
\end{tabular}

\section{Partnerships}

The partnerships section of the LTS program design requires a consideration of the key support people or organizations, the key activities these partners provide, and the resources acquired from them that enables the LTS effort to proceed. Examples of activities provided by these partnerships that were provided were: fundraising, marketing, evaluation, acquisition of needed resources, and facilitation of institutional requirements. Many participants simply listed the entity with which they would be partnering without expanding to what value was provided, but many of the values can be inferred. 
Of the 34 blueprints, 30 included partnerships with a minimum of 1 , a maximum of 15 , and a median of 6 . The partnership listed most often was with the University/College for the handling of logistics for connection to projects, funding, and travel coordination among others. Further partnerships included those with the Intermediary for networking, Donors for funding, and Industry and Engineering Faculty for assistance with design. Some of the more unique and thoughtful partnerships were those with Local Experts for their help with design, the Client/Community for implementation of the project, and a partnership with the Students to achieve maximum potential of learning and community benefit. These ideas are examples of best practices, which are also reflected in the literature. ${ }^{35,48,58}$ Table VII lists some of the partnerships that were most frequently described by the participants, but is certainly not exhaustive (for example, five mentioned that personal relations were important).

TABLE VII

ASSISTANCE PROVIDED BY PARTNERSHIPS (\% OF ALL PROGRAMS), N=30

\begin{tabular}{lllll}
\hline \multicolumn{1}{c}{ Community } & University/College & \multicolumn{1}{c}{ Intermediary } & \multicolumn{1}{c}{ Donors } & Other Faculty \\
\hline Implementation (13) & Logistics (80) & Networking (37) & Funding (37) & Design (33) \\
Experts (7) & Public Relations (23) & Logistics (23) & Mentoring (17) & Inspiration (13) \\
& Networking (20) & Data (7) & & Instruction (7) \\
& Assessment (3) & Funding (7) & & \\
\hline
\end{tabular}

\section{Value Streams: Returns}

The assumption is that the value delivered by the LTS program should be worth it to the stakeholders, and that the program reflects this through multiple intentionally designed means. One should consider for what value are the stakeholders willing to pay (financially, or otherwise), what/how do stakeholders currently contribute/pay, in what forms they return value, how would the stakeholders prefer to contribute, and how much does each value stream contribute to the overall success of the LTS program. A few examples are: supporter donations for program costs; scholarly publications for faculty; media coverage to promote the program; professional development for students; health benefits for community; fees to cover program costs.

Thirty-one of the 34 participants indicated some return value streams on their blueprint, with a minimum of 3 ideas, a maximum of 16, and a median of 6 . A summary of these ideas is presented in Table VIII. The results are interesting to contemplate: some support the altruistic call to LTS while others are self-serving. The participants generally understood the value stream returns to each stakeholder for their involvement as demonstrated by their provided examples. Though similar to the earlier described value proposition, the returns are skewed towards the practitioner and students and away from the community partners. Unlike value propositions, the "civic learning" side for students received less recognition here, with the exception of one blueprint that included "enhances desire to serve". Perhaps this idea of civic learning was also included within the statement of "student development" that frequently appeared on the blueprints. One new feature in this section that is different from the value proposition, are returns to the program in terms of sustainability of the program, and further support in terms of funding, mentoring, and more. In addition, some general statements were made where the stakeholder 
receiving the benefit was unclear and therefore the value streams may have applied more broadly; these included items such as: love for engineering, joy, good feelings, enthusiasm, energy.

Table VIII

VALUE STREAMS - RETURNS (\% OF ALL PROGRAMS), N=31

\begin{tabular}{|c|c|c|c|c|}
\hline Students & Community & Lead & University & Program \\
\hline Personal development (39) & Tangible good(48) & Scholarship/tenure (48) & PR/recruiting (39) & Sustainability (39) \\
\hline Global awareness (29) & & Satisfaction (32) & & \\
\hline Academic satisfaction (29) & Relationships (19) & Recognition (13) & Retention (6) & Further support (19) \\
\hline Academic learning (26) & & Learning (6) & & \\
\hline $\begin{array}{l}\text { Professional skills (23) } \\
\text { Fun (3) }\end{array}$ & Voice (3) & Personal development (1) & $\begin{array}{l}\text { Help meeting } \\
\text { mission }(3)\end{array}$ & \\
\hline
\end{tabular}

\section{Value Streams: Costs and Outlays}

The ninth and last box on the LTS program design blueprint requires an assessment of the important costs inherent in the program model. The costs associated with the program activities should be assessed, and evaluated in terms of the value that they provide. The expenses associated with the key resources should also be evaluated relative to their value. A few examples of costs and outlays are: fixed costs like tuition; variable costs like available time, energy, enthusiasm; economies of program scale; economies of program scope; and activities that place value at risk.

Of the 34 blueprints, 32 listed costs for their LTS program, ranging from 2 to 13 ideas on a single blueprint, with a median of 6 . Table IX summarizes the most commonly cited costs. These costs overlap to a large degree with the "resources" considered above in design element 6 (Table VI).While time for all stakeholders and funding for most were the major costs included by the participants, efforts for coordination by administration and practitioners also frequently cited. Time and money were routinely mentioned as common barriers to frequent, or scalable, LTS efforts and should be expected when in the earliest stages of program conceptualization. These perceived barriers have been identified in other studies of faculty. ${ }^{1,19}$ Some of the more interesting costs included liability, passion, and comfort with ambiguity.

Table IX

VALUE STREAMS - COSTS AND OUTLAYS (\% OF ALL PROGRAMS), N=32

\begin{tabular}{lclll}
\hline \multicolumn{1}{c}{ Students } & Community & \multicolumn{1}{c}{ Lead } & \multicolumn{1}{c}{ University } & \multicolumn{1}{c}{ Program } \\
\hline Funding (22) & [None] & Time (88) & Funding (16) & Funding (91) \\
Time (19) & & Coordination (41) & Time (16) & Quality (16) \\
Energy (3) & & Opportunity (25) & Coordination (6) & \\
Ambiguity (3) & & Energy (19) & & \\
& & Passion (13) & & \\
& & Assessment (6) & & \\
\hline
\end{tabular}

Interestingly, the program participants did not explicitly note any costs to the community except that one noted that the intermediary would have a cost in coordination. However, in some cases the statements in this section of the blueprint were so vague that they were perhaps mis- 
attributed to a single stakeholder. For example, one blueprint listed "personal time- passion is finite"). This was interpreted as the personal time of the LTS faculty leader, but perhaps it was intended to be more inclusive of the time from all stakeholders. It can also be assumed that the intermediaries would have financial costs as well, but none mentioned potential financial costs to the communities served. Clearly the veracity of this assumption should be carefully considered, and discussed with potential partners. LTS programs certainly expect the community to invest time and energy into the partnership. ${ }^{49,59-60}$ Some community partners also supply money, directly or in-kind. Frequently the community is also a key source of energy and passion for the project. $^{59}$ It is important that all of the LTS partners have a clear and realistic understanding of the costs and outlays required by each party.

\section{Assessment}

Although assessment was not a stand-alone box on the blueprint, an assessment plan should be crafted to evaluate critical LTS elements. Well-designed strategies to measure the value and success of the LTS programs is a clear mark of sustainable offerings. For S-L courses this is expected to include the standard measures used to assess student learning that are used to award grades, but it should also include a richer variety of assessments to evaluate the value delivered to all stakeholders. At a minimum, some measures of community benefits and satisfaction should be included. Assessments can span quantitative and qualitative measures, although qualitative information can be converted into quantitative formats via scoring rubrics. Reflection is a particularly powerful activity that can both increase student learning via metacognition and assess many nuanced impacts on students. Rigorous S-L demands that student reflections are included as part of the learning process, and these artifacts can be used for program assessment. $^{54,61-32}$ Community reflections could also be used as an effective method for continuing advancement of the project and ensuring that the benefits proposed by the LTS program are received and acknowledged by the community. Among workshop attendees, assessment was routinely mentioned as an area of importance but also unfamiliarity and, hence, discomfort. Participants, not surprisingly, preferred quantitative assessment instruments, despite their limitations. For improved chances of delivering value, LTS design and management teams should ideally include an assessment expert for formative evaluation, and if they are not available for routine engagement, then as a project partner providing occasional evaluation of summative outcomes.

\section{CONCLUSIONS AND FURTHER STUdY}

Thinking through the nine critical LTS program elements using the blueprint provides a structured and effective method to help increase the positive impacts of LTS in engineering. For simplicity in a workshop format, blueprint elements 2 and 8 (value proposition and value streams: returns) could be combined to a single element, since these ideas overlap. The workshop participants generally had similar thoughts for both of these elements, although given more time the value streams could be refined with quantifiable measures that provide clear targets for program monitoring and assessment. The same simplification is possible for blueprint elements 6 and 9 (resources and value streams: costs \& outlays), yet a detailed cost assessment would likely prepare program designers for fiscal and workload realities. Condensing these similar elements and adding in assessment results in a total of eight design elements, and could 
provide a good first draft blueprint, while permitting detailed planning later. Overall, the workshop participants who had more experience (six or more years) described more fully their programs and included a wider and more practical understanding for each design element on the LTS blueprint. Additionally, the community's concerns and input were more highly valued by these experienced leaders compared to some of the other blueprints that were mostly concerned with student outcomes. These more experienced practitioners realize that, for a program to be sustainable, all stakeholders need to be valued collaborators, and their opinions of the project considered to sustain relationships beyond a one-time experience. The blueprint, thus, enables LTS practitioners to think critically of their LTS efforts holistically on the front end of the process, not only in the middle or the end. It is our hope that the blueprint will be used as a formative and summative evaluation tool to lead to more sustainable LTS efforts and practices.

The research team plans to receive completed blueprints from additional LTS practitioners to develop a library of projects as a reference for future LTS designers. Using these for inspiration, potential practitioners can make their own blueprint (a blank copy of the blueprint can be obtained by emailing the corresponding author). The intent is that more practitioners, now equipped with an LTS program design guide, will think holistically through the system of their programs with all involved such that these programs can yield their rich potential, effectively and sustainably. Thus the blueprint could be used as a tool to facilitate discussion among key stakeholders in the LTS program (such as leaders, community partners, and students), and revisited over time as the program evolves. It is also of value to have a common blueprint template among the LTS engineering education community as a means to share LTS efforts and disseminate LTS programs.

\section{ACKNOWLEDGMENT}

This material is based upon work supported by the National Science Foundation under DUE Grant Nos. 1022927, 1022883, 1022738, 1023022, and 1022831. Any opinions, findings, and conclusions or recommendations expressed in this material are those of the author(s) and do not necessarily reflect the views of the National Science Foundation. Thank you to participants of the September 2011 LTS expert meeting: William Oakes, Dwight Giles, Chris Rogers, Holly Keyes Ault, Thomas Colledge, Mandar Dewoolkar, Mark Fitch, Camille George, Trevor Harding, Jeffrey Howard, Craig Just, Marybeth Lima, Kate McPherson, Spencer Magleby, Margie Pinnell, David Schaad, Pamela Steinke, Edmund Tsang, Michael Diamond, Mark Henderson, Juan Lucena, Susan McCahan, Robyn Sandekian, and Edward Zlotkoswki. The authors also thank the participants of our 2012 LTS workshops: Michelle Adeoye, BasemAlzahabi, Shannon Bartelt-Hunt, Jeff Brown, Adam Carberry, George Catalano, Casey Cline, Thomas Colledge, Ryan DuPont, NduEgekeze, Islam El-Adaway, Jacqueline Fritsch, ArbiGhazarian, Laura Hosman, Bent Jesiek, Shawn Jordan, William Kisaalita, Micah Lande, Randy Lewis, Bruce Litchfield, Juan Lucena, John Lumkes, Laurie McNeill, Jay Meegoda, Curtis Nelson, Jo-Ann Panzardi, Mary Raber, Dan Saulnier, Carol Sevier, Dana Sherman, Julia Thompson, KarinnaVernaza, Theresa Vitolo, ValeriWerpetinski, Malinda Zarske. 
International Journal for Service Learning in Engineering Special Edition, pp. 64-83, Fall 2013

ISSN 1555-9033

\section{REFERENCES}

${ }^{1}$ Paterson, K., C. O'Holleran, C. Leslie. 2010. "Faculty impressions of service learning in engineering education." American Society for Engineering Education (ASEE) Annual Conference and Exposition Proceedings, Louisville, KY, June 20-23, 2010.

${ }^{2}$ Barrington, L., J. Duffy. 2010. "Maximizing benefits of service-learning in engineering." American Society for Engineering Education (ASEE) Annual Conference and Exposition Proceedings, Louisville, KY, June 20-23, 2010.

${ }^{3}$ Bielefeldt, A.R., K.G. Paterson, and C.W. Swan. 2010. "Measuring the Value Added from Service Learning in Project-Based Engineering Education." The International Journal of Engineering Education, 26 (3): 535-546.

${ }^{4}$ Lima, M., W. Oakes. 2006. Service-Learning: Engineering in Your Community. Oxford University Press.

${ }^{5}$ Oakes, W., M. Thompson. 2005. "Institutionalizing service-learning into a first-year engineering curriculum." American Society for Engineering Education (ASEE) Annual Conference and Exposition Proceedings, Portland, OR, June 12-15, 2005.

${ }^{6}$ Zarske, M., D. Reamon, D. Knight, A. Bielefeldt. 2012. "Service-Based First Year Engineering Projects: Do they make a difference?" American Society for Engineering Education (ASEE) Annual Conference and Exposition Proceedings, San Antonio, TX, June 10-13, 2012.

${ }^{7}$ Freeman, S.F., R. Whalen, B.K. Jaeger, S.M. Forman. 2012. "Service-learning vs. learning service in first-year engineering: if we cannot conduct first-hand service projects, is it still of value?" American Society for Engineering Education (ASEE) Annual Conference and Exposition Proceedings, San Antonio, TX, June 10-13, 2012.

${ }^{8}$ Bielefeldt, A.R., M.M. Dewoolkar, K.M. Caves, B.W. Berdanier, and K.G. Paterson. 2011. "Diverse Models for Incorporating Service Projects into Engineering Capstone Design Courses." International Journal of Engineering Education 27(6): 1206-1220.

${ }^{9}$ Duffy, J., C. Barry, L. Barrington, M. Heredia. 2009. "Service-learning in engineering science courses: does it work?" American Society for Engineering Education (ASEE) Annual Conference and Exposition Proceedings, Austin, TX, June 14-17, 2009.

${ }^{10}$ Vitolo, T.M., K.M. Vernaza, B.J. Brinkman, S.E. Steinbrink. 2013. "Assessing impact without using grades: quality review of community engagement." American Society for Engineering Education (ASEE) Annual Conference and Exposition Proceedings, Atlanta, GA, June 23-27, 2013.

${ }^{11}$ Gokhale, S. and M. O’Dea. 2000. "Effectiveness of community service in enhancing student learning and development." American Society for Engineering Education (ASEE) Annual Conference and Exposition Proceedings, St. Louis, MO, June 18-22, 2000.

${ }^{12}$ Zoltowski, C., W. Oakes, B. Myers. 2006. "Multi-campus collaborations among undergraduate design teams: opportunities and challenges." American Society for Engineering Education (ASEE) Annual Conference and Exposition Proceedings, Chicago, IL, June 18-21, 2006.

${ }^{13}$ Yurttas, L., J. Christensen, J.S. Haney, M. El-Halwagi, J. Froyd, C. Glover. 2007. "Enhancement of chemical engineering introductory curriculum through service learning implementation." American Society for Engineering Education (ASEE) Annual Conference, Honolulu, HI, June 24-27, 2007.

${ }^{14}$ Cho, C-S., C. Mazze, S.L. Kika, G.B. Gehrig. 2013. "Enhancing student learning and engagement in construction course using service learning." American Society for Engineering Education (ASEE) Annual Conference and Exposition Proceedings, Atlanta, GA, June 23-26, 2013. 
${ }^{15}$ Everett, J., Y. Mehta, J.R. Wyrick, M. Perez-Colon. 2009. "Engineers Without Borders: experiential education." American Society for Engineering Education (ASEE) Annual Conference and Exposition Proceedings, Austin, TX, June 14-17, 2009.

${ }^{16}$ Jaeger, B., E. LaRochelle. 2009. “EWB^2 Engineers Without Borders: Educationally, a World of Benefits.” American Society for Engineering Education (ASEE) Annual Conference and Exposition Proceedings, Austin, TX, June 14-17, 2009.

${ }^{17}$ Gordon, R., A. Gordon, P. Bendient, 2006. "Rice University Engineers Without Borders: An Exercise in International Service Learning." American Society for Engineering Education (ASEE) Annual Conference and Exposition Proceedings, Chicago, IL, June 18-21, 2006.

${ }^{18}$ Reichle, S., A. Bang, C. Considine. 2009. "International service-learning projects for senior capstone projects." American Society for Engineering Education (ASEE) Annual Conference and Exposition Proceedings, Austin, TX, June 14-17, 2009.

${ }^{19}$ Pierrakos, O., A. Zilberberg, C. Swan, J. Duffy, J. Paterson, A. Bielefeldt, N. Canney. 2012. "Initial Findings from the Faculty Survey on Learning Through Service." American Society for Engineering Education (ASEE) Annual Conference and Exposition Proceedings, San Antonio, TX, June 10-13, 2012.

${ }^{20}$ Tucker, B.G., D.O. Kazmer, O. Pierrakos, C. Swan, A.R. Bielefeldt, K. Paterson, A. Soisson. 2013. "Faculty Perspectives on Learning Through Service in Engineering Education: Challenges and Opportunities." American Society for Engineering Education (ASEE) Annual Conference and Exposition Proceedings, Atlanta, GA, June 23 $27,2013$.

${ }^{21}$ Vandersteen, J.D.J., C.A. Baillie, K.R. Hall. 2009. "International humanitarian engineering: Who benefits and who pays?" IEEE Technology and Society Magazine28 (4): 32-41.

${ }^{22}$ Stewart, T., N. Webster, eds. 2011. Exploring Cultural Dynamics and Tension Within Service-Learning. Information Age Publishing, Inc. http://www.servicelearning.org/library/resource/9443

${ }^{23}$ Burack, C., Duffy, J., Melchior, A., \& Morgan, E. 2008. "Engineering faculty attitudes toward service-learning." American Society for Engineering Education (ASEE) Annual Conference and Exposition Proceedings, Pittsburgh, PA, June 22-24, 2008.

${ }^{24}$ Howard, J. 2001. "Principles of Good Practice for Service-Learning Pedagogy." Michigan Journal of Community Service Learning: Service-Learning Course Design Workbook, University of Michigan: OCSL Press, Summer, pp. 16-19

${ }^{25}$ Kendall, J. \& Associates. 1990. Principles of Good Practice in Combining Service and Learning. Combining Service and Learning. National Society for Internships and Experiential Education, Raleigh NC.

${ }^{26}$ Honnet, E.P., S.J. Poulsen. 1989. Principles of Good Practice for Combining Service and Learning. Wingspread Special Report, The Johnson Foundation Inc., Racine.

${ }^{27}$ Sigmon, R.L. 1979. “Service-Learning: Three Principles.” Synergist, 8, 9-11.

${ }^{28}$ Sandmann, L.R., R.C. Kiely, R.S. Grenier. 2009. "Program Planning: The Neglected Dimension of ServiceLearning." Michigan Journal of Community Service Learning. Spring, 17-33.

${ }^{29}$ Bielefeldt, A., K. Paterson, J. Duffy, C. Swan, O. Pierrakos, N. Canney. 2012. "Engineering Faculty Engagement in Learning Through Service Summit: Best Practices and Affinity Mapping." American Society for Engineering Education (ASEE) Annual Conference and Exposition Proceedings, San Antonio, TX, June 10-13, 2012.

${ }^{30}$ Osterwalder, A. and Y. Pigneur. 2010. Business Model Generation. John Wiley \& Sons. 280 pp. 
International Journal for Service Learning in Engineering Special Edition, pp. 64-83, Fall 2013

ISSN 1555-9033

${ }^{31}$ Bielefeldt, A., K. Paterson, C. Swan, O. Pierrakos, D.O. Kazmer, A. Soisson. 2013. "Spectra of Learning Through Service Programs." American Society for Engineering Education (ASEE) Annual Conference and Exposition Proceedings, Atlanta, GA, June 23-27, 2013.

${ }^{32}$ Swan, C., A.R. Bielefeldt, K. Paterson, D.O. Kazmer, O. Pierrakos, A. Soisson, B.G. Tucker. 2013. "Workshops for the Engineering Faculty Engagement in Learning Through Service (EFELTS) Project: Development and Initial Findings." American Society for Engineering Education (ASEE) Annual Conference and Exposition Proceedings, Atlanta, GA, June 23-27, 2013.

${ }^{33}$ Attride-Stirling, Jennifer. 2001. "Thematic networks: an analytic tool for qualitative research." Qualitative research 1 (3): 385-405.

${ }^{34}$ NVivo qualitative data analysis software. 2012. QSR International Pty Ltd. Version 10.

${ }^{35}$ Sandmann, L.R., T.L. Moore, J. Quinn. 2012. "Center and Periphery in Service-Learning and Community Engagement: A Postcolonial Approach.” In: Understanding service-learning and community engagement: crossing boundaries through research; Eds. J.A. Hatcher, R.G. Bringle. Information Age Publishing, Charlotte NC.

${ }^{36}$ d'Arlach, L., B. Sanchez, R. Feuer. 2009. "Voices from the Community: A Case for Reciprocity in ServiceLearning." Michigan Journal of Community Service Learning, 16(1), 5-16.

${ }^{37}$ Kliewer, B., Sandmann, L.R.; Kim, J., Omerikwa, A. 2010. “Toward Understanding Reciprocity In CommunityUniversity Partnerships: An Analysis of Theories of Power." Proceedings of the Adult Education Research Conference. P. 256-261.

http://www.adulterc.org/Proceedings/2010/proceedings/kliewer_etal.pdf Accessed Nov. 18, 2013.

${ }^{38}$ Jameson, J.; Clayton, P.; Jaeger, A. 2010. Community engaged scholarship as mutually transformative partnerships. In: Participatory partnerships for social action and research, Editor(s): Hater, L.; Hamel-Lamber, J.; Millesen, J. Pages: 259-277 Kendall Hunt, Dubuque, IA

${ }^{39}$ Miller, M. M., Hafner, P. M. 2008. "Moving toward dialogic collaboration: A critical examination of a universityschool-community partnership.” Educational Administration Quarterly. 44 (1), 66-110.

${ }^{40}$ Moore, T.; Sandmann, L.; Quinn, J. 2008. "International engagement: A critical discussion.” Annual Meeting of the Association for the Study of Higher Education. Jacksonville, FL, Nov. 5-8.

${ }^{41}$ Santas, A,J. 2009. "Reciprocity Within Biochemistry and Biology Service-Learning." Biochemistry and Molecular Biology Education. 37 (3), 143-151.

${ }^{42}$ Jacoby, B. and Associates. 1996. Service-Learning in Higher Education: Concepts and Practices. Jossey-Bass, San Francisco.

${ }^{43}$ Bringle, R.G., M.A. Phillips, M. Hudson. 2004. The Measure of Service Learning: Research Scales to Assess Student Experiences, 227 pp. American Psychological Association, Washington D.C.

${ }^{44}$ Furco, A. 1996. Service-Learning: A Balanced Approach to Experiential Education. Expanding Boundaries: Serving and Learning. Washington DC: Corporation for National Service, 2-6.

${ }^{45}$ Lyday, W. J., L. Winecoff. 1998. Connecting Communities through Service Learning. Clemson, SC: National Dropout Prevention Center.

${ }^{46}$ Stoecker, R., E. Tryon. 2008. Unheard Voices: Community Organizations and Service Learning. Chapter 1, pg. 67. Temple University Press, Philadelphia PA. 
International Journal for Service Learning in Engineering Special Edition, pp. 64-83, Fall 2013

ISSN 1555-9033

${ }^{47}$ Thompson, J.D., B.K. Jesiek. 2011. "Work in Progress: Project-Based Service Learning in Engineering: Investigating Partner Relationships." Proceedings of the $41^{\text {st }}$ ASEE/IEEE Frontiers in Education (FIE) Conference. Oct. 12-15, Rapid City, SD. IEEE. S3B-1-2.

${ }^{48}$ Duffy, J. 2008. "Village Empowerment: Service-Learning with Community.” International Journal for Service Learning in Engineering. 3 (2), 1-17.

${ }^{49}$ Petri, A.N. 2012. Reciprocal Exchange: Understanding the Community Partner Perspective in Higher Education Service-Learning. Dissertation. University of Missouri - Kansas City.

${ }^{50}$ Tryon, E.A., A. Hilgendorf, Scott. 2009. The Heart of Partnership: Communication and Relationships. Chapter 6 in: The Unheard Voices: Community Organizations and Service Learning. Eds. R. Stoecker, E.A. Tryon. P. 96-115. Temple University Press. Philadelphia, PA.

${ }^{51}$ Hatcher, Julie A., and Robert G. Bringle. 1997. "Reflection: Bridging the gap between service and learning." College teaching 45.4. 6pp.

${ }^{52}$ Eyler, Janet, and Dwight E. Giles Jr. 1999. "Where's the Learning in Service-Learning?” Jossey-Bass Higher and Adult Education Series. Jossey-Bass, Inc., San Francisco, CA 94104, 1999.

${ }^{53}$ Slivovsky, L.A., F.R. DeRego, L.H. Jamieson, W.C. Oakes. 2003. "Developing the Reflection Component in the EPICS Model of Engineering Service Learning." Proceedings of the 33rd ASEE/IEEE Frontiers in Education Conference. Nov. 5-8, Boulder, CO. S1B-14-19.

${ }^{54}$ Huyck, M., K. Bryant, D. Ferguson. 2009. "The impact of reflections in service learning and other undergraduate team project learning." American Society for Engineering Education (ASEE) Annual Conference and Exposition Proceedings, Austin, TX, June 14-17, 2009.

${ }^{55}$ Warnock, S., M. Kahn. 2007. "Expressive / Exploratory Technical Writing (XTW) in Engineering: Shifting the Technical Writing Curriculum.” J. Technical Writing and Communication, 37 (1), 35-57.

${ }^{56}$ Schneider, J., J. A. Leydens, J. Lucena. 2008. "Where is 'Community’?: Engineering education and sustainable community development." European Journal of Engineering Education 33 (3), 307-319.

${ }^{57}$ Catalano, G.D. 2011. "Unlocking the heart of engineering grand challenges: listening to the quiet voices." American Society for Engineering Education (ASEE) Annual Conference and Exposition Proceedings, Vancouver, BC, June 26-29, 2011.

${ }^{58}$ McArthur, P.M. 2010. Case Study: Community Perspectives of a Service Learning Partnership Involving One School of Nursing in the Southeastern United States.” Ph.D. Dissertation, University of Tennessee.

${ }^{59}$ Blouin, D.D., E.M. Perry. 2009. "Whom Does Service Learning Really Serve? Community-Based Organizations' Perspectives on Service Learning." Teaching Sociology, 37 (2), 120-135.

${ }^{60}$ Tryon, E., R. Stoecker, A. Martin, K. Seblonka, A. Hilgendorf, M. Nellis. 2008. "The Challenge of Short-Term Service Learning.” Michigan Journal of Community Service Learning, 15, 16-26.

${ }^{61}$ Olds, B. 2000. "Reflection as an assessment measure." American Society for Engineering Education (ASEE) Annual Conference and Exposition Proceedings, St. Louis, MO, June 18-22, 2000.

${ }^{62}$ Whitman, L.E., C. Mason. 2013. “Assessing service learning reflections.” American Society for Engineering Education (ASEE) Annual Conference and Exposition Proceedings, Atlanta, GA, June 23-27, 2013. 